\title{
Therapeutic effect against retinal neovascularization in a mouse model of oxygen-induced retinopathy: bone marrow- derived mesenchymal stem cells versus Conbercept
}

\author{
Wei $\mathrm{Xu}^{1+}$, Weijing Cheng ${ }^{1,2+}$, Xiaoyuan $\mathrm{Cui}^{1}$ and Guoxing $\mathrm{Xu}^{1,2^{*}}$
}

\begin{abstract}
Background: To study the therapeutic effect of bone marrow-derived mesenchymal stem cells (BMSC) against retinal neovascularization and to compare with anti-vascular endothelial growth factor (VEGF) therapy.

Methods: Neonatal C57BL/6 mice were exposed in hyperoxygen and returned to room air to develop oxygeninduced retinopathy (OIR). Red fluorescent protein-labeled BMSC and Conbercept were intravitreally injected into OIR mice, respectively. Inhibition of neovascularization and apoptosis in OIR mice were assessed through retinal angiography, histopathology and terminal deoxynucleotidyl transferase-mediated dUTP nick end labeling (TUNEL) assay.

Results: BMSC were able to migrate and integrate into the host retina, significantly inhibit retinal neovascular tufts and remodel the capillary network after injecton. Treatment with BMSC increased the retinal vascular density, decreased the number of acellular capillaries and inhibited retinal cell death. This effect was not inferior to current anti-VEGF therapy by using Conbercept.
\end{abstract}

Conclusions: Intravitreal injection of BMSC exerts a protective effect against retinal neovascularization and offers a therapeutic strategy for oxygen-induced retinopathy.

Keywords: Retinal neovascularization, Oxygen-induced retinopathy, Mesenchymal stem cell, Vascular endothelial growth factor, Therapy

\section{Background}

Pathological retinal neovascularization is a major cause of visual diminution and at times even leads to blindness. It refers to the incomplete and unhealthy architecture of the vasculature in many retinal diseases, such as diabetic retinopathy, retinopathy of prematurity and retinal vein occlusion. These diseases involve damage of the retinal vessels, causing exudation of the fluid, hemorrhage or vessel obstruction, and proliferation. This

\footnotetext{
* Correspondence: fjmuxuguoxing@126.com

tWei Xu and Weijing Cheng contributed equally to this work ${ }^{1}$ Department of Ophthalmology, The First Affiliated Hospital of Fujian Medical University, 20 Chazhong Road, Fuzhou City 350005, China

${ }^{2}$ Fujian Institute of Ophthalmology, Fuzhou, China
}

in turn results in retinal ischemia that is associated with severe disorders, such as neovascularization, vitreous hemorrhage and tractional retinal detachment [1].

Anti-vascular endothelial growth factor (VEGF) therapy has led to a breakthrough in the treatment of retinal neovascularization [2]. However, anti-VEGF therapy remains to be controversial in several aspects [3]. For instance, hypertension was discovered when treated with bevacizumab, and lead to other cardiovascular complications [4]. Furthermore, VEGF-A plays an important role as a retinal neuro-protectant, and its blockade under retinal stress conditions accelerates retinal cell death [5]. Emerging research has shown that anti-VEGF-A therapy might be associated with retinal atrophy [6]. Therefore,

(c) The Author(s). 2020 Open Access This article is distributed under the terms of the Creative Commons Attribution 4.0 International License (http://creativecommons.org/licenses/by/4.0/), which permits unrestricted use, distribution, and reproduction in any medium, provided you give appropriate credit to the original author(s) and the source, provide a link to the Creative Commons license, and indicate if changes were made. The Creative Commons Public Domain Dedication waiver (http://creativecommons.org/publicdomain/zero/1.0/) applies to the data made available in this article, unless otherwise stated. 
developing innovative therapeutic strategies against retinal neovascularization is imperative.

Mesenchymal stem cells (MSC) are self-renewing multipotent cells that are presented in the mesenchymal tissues and play important roles in tissue regeneration and injury repair [7]. Recently, important progress has been achieved in understanding the mechanisms of MSC homing and recruitment to the ischemic myocardium [8]. They can be recruited into the neovascularized areas and applied for anti-tumor therapy [9]. MSC could also secrete paracrine factors to promote vascular regeneration [10].

Since MSC are involved in angiogenesis and tissue repair, we decided to investigate the roles of bone marrow-derived mesenchymal stem cells (BMSC) that play during retinal neovascularization in a mouse model of oxygen-induced retinopathy (OIR) to simulate pathogenesis of retinopathy of prematurity. The therapeutic effect of BMSC was compared to Conbercept (Kanghong, Inc., Chengdu, China) which is a fusion protein composed of extracellular domain 2 of VEGF receptor 1 and extracellular domains 3 and 4 of VEGF receptor 2. Intravitreal injection of BMSC, compared to Conbercept, was similarly found to inhibit retinal neovascularization and remodel the capillary network. Besides, BMSCs in our study are proved that it could be able to migrate and integrate into the host retina, which offer a promising treatment strategy for neovascular diseases.

\section{Methods}

\section{Cell preparation}

Commercially available red fluorescent protein-labeled BMSC of C57BL/6 mouse (RFP-BMSC, Catalog No. MUBMX-01201, Cyagen, Guangzhou, China) were cultured to determine the expressions of CD44, CD29, Sca1, CD31 and CD117, and tested for osteogenic and adipogenic differentiation. The cells were harvested and diluted in Dulbecco's modified Eagle's medium (DMEM, Cyagen, Guangzhou, China) at different concentrations for injection (ranged from $5 \times 10^{6}$ cells $/ \mathrm{ml}$ to $1 \times 10^{8}$ cells $/ \mathrm{ml})$.

\section{Animal experiments}

All animal experiments were approved by the animal ethical committee of the Fujian Medical University, and performed in accordance with the National Institutes of Health Guide for the Use of Laboratory Animals. Pregnant C57BL/6 mice (Subline J, Specific pathogen free class) were purchased from Slaccas Animals (Shanghai, China) and housed in room air (21\% oxygen) at $25^{\circ} \mathrm{C}$ with free access to food and water. After delivery, the neonates together with their mother were exposed to $75 \%$ oxygen (hyperoxygen) from postnatal day 7 (P7) to P12 and returned to room air to develop oxygen- induced retinopathy (OIR). Litters at P12 $(5.8 \pm 0.2 \mathrm{~g}$ in weight) were anesthetized and randomly grouped according to the treatments: intravitreal injection of DMEM (1 $\mu \mathrm{l})$ (OIR-DMEM group), intravitreal injection of RFP-BMSC ( $1 \mu \mathrm{l}$, OIR-BMSC group) and intravitreal injection of Conbercept ( $1 \mu \mathrm{l}$, Kanghong, Inc., Chengdu, China) (OIR-CON group). The litters without hyperoxygen exposure (healthy group) and litters without treatment after hyperoxygen exposure (OIR-blank group) were set as controls.

\section{Retinal angiography}

Mice were anesthetized with an intraperitoneal injection of ketamine $(90 \mathrm{mg} / \mathrm{kg})$ and xylazine $(8 \mathrm{mg} / \mathrm{kg})$, and administered intraventricular injection of $0.3 \mathrm{ml}$ of FITC-dextran (2000 kDa, 50 mg/ml, Sigma-Aldrich, MO, USA). After 5 minutes, the mice were euthanized by intraperitoneal injection of sodium pentobarbital $(200 \mathrm{mg} /$ $\mathrm{kg}$ ) and the eyes were enucleated and then fixed with $4 \%$ paraformaldehyde for $2 \mathrm{~h}$. The corneas and the lenses were removed under a stereo microscope (66 VisionTech, Suzhou, China). The retinas were carefully dissected and flat-mounted on a glass slide with antifluorescent quenching solution. The retinal vessels were viewed by fluorescence microscopy (Zeiss Axiophot, NY, USA). The avascular areas and neovascular tuft areas were assessed to evaluate the aspects of angiogenesis and treatment outcomes. The retinas were digested in $3 \%$ trypsin (Gibco, CA, USA) for $2-3 \mathrm{~h}$ at $37^{\circ} \mathrm{C}$ to isolate the retinal vasculature. Subsequently, the retinal vasculature was stained with periodic acid-Schiff reagent and hematoxylin to investigate the capillary network.

\section{Retinal histopathology and TUNEL assay}

Mice were euthanized by intraperitoneal injection of sodium pentobarbital $(200 \mathrm{mg} / \mathrm{kg})$ and eyes were enucleated and immediately placed in $4 \%$ paraformaldehyde for $24 \mathrm{~h}$, dehydrated using a graded ethanol series, and embedded in paraffin. Sagittal sections were cut from each eye. Serial sections of $5 \mu \mathrm{m}$ thickness were cut, deparaffinized in xylene and then hydrated. Hematoxylin and eosin staining was used to quantify neovascularization by counting the vascular nuclei that are extended anteriorly from the internal limiting membrane into the vitreous. The average number of neovascular nuclei per section was calculated in each group. The retinal vascular nuclei were counted using a masked protocol by light microscopy (magnification, 100-250). A terminal deoxynucleotidyl transferase-mediated dUTP nick end labeling (TUNEL) assay kit was used to test apoptosis in the retinal sections according to the manufacturer's instructions (Roche, IN, USA). Images were captured under a Zeiss fluorescence microscope. The number 
of TUNEL-positive cells was calculated by Image-Pro plus 6.0. Images from random quadrant of posterior retinas were selected and masked to investigators for statistical analysis.

\section{Statistical analysis}

Each experiment was replicated three times. The normally distributed data are presented as mean \pm standard deviation (SD). One-way ANOVA was used for comparison among groups in each independent experiment followed by LSD test as post-hoc analysis. Statistical significance was set at $P<0.05$.

\section{Results}

Evaluation of retinal neovascularization

After hyperoxygen exposure from postnatal day 7 (P7) to P12, the neonatal mice developed OIR in the room air. OIR reached a peak severity at P17 during observation. The retinas were flat-mounted and examined at P17 to evaluate the vascular morphology in different groups. The superficial and deep vascular layers that are extended from the optic nerve to the periphery were observed in the retinas of healthy group, which showed the existence of fewer neovascular complexes. In contrast, multiple neovascular tufts and central avascular areas were observed in the retinas of
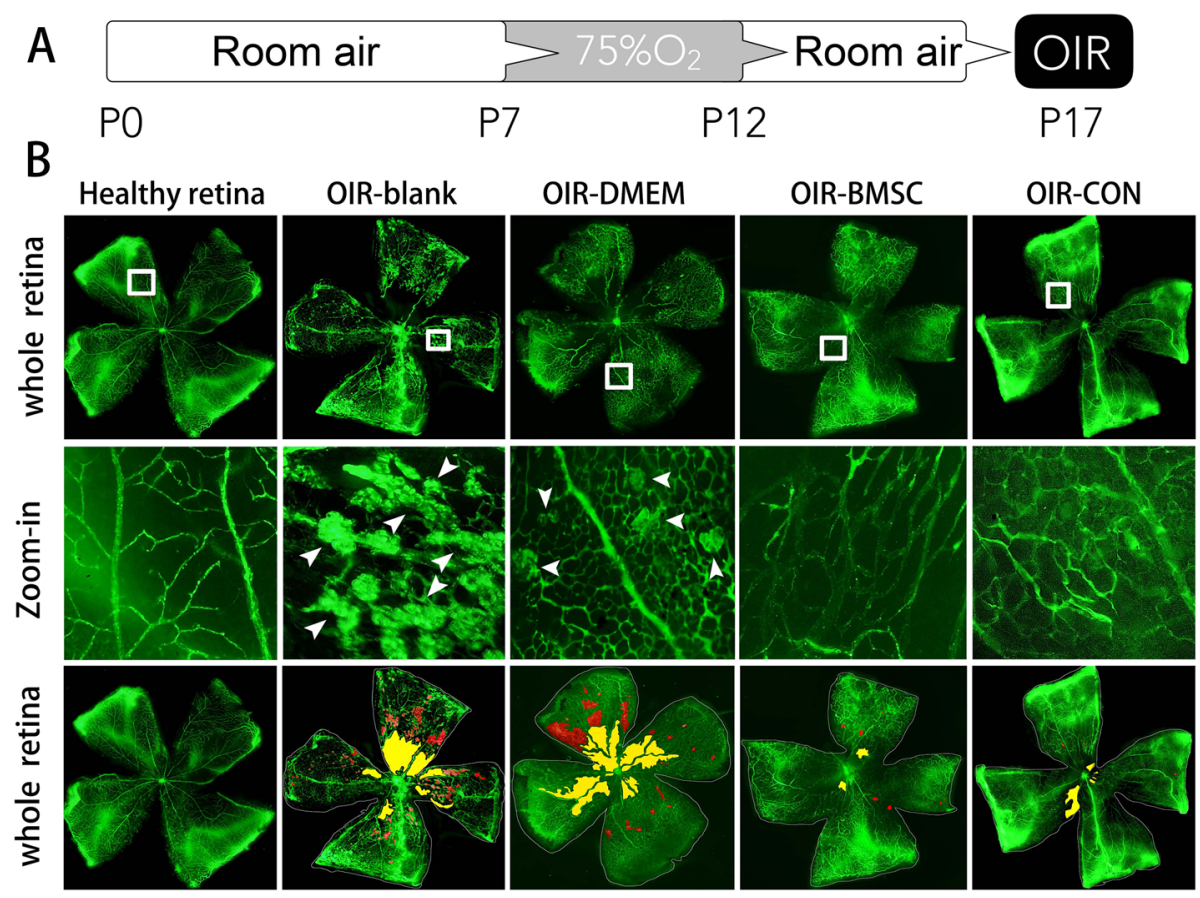

Avascular area

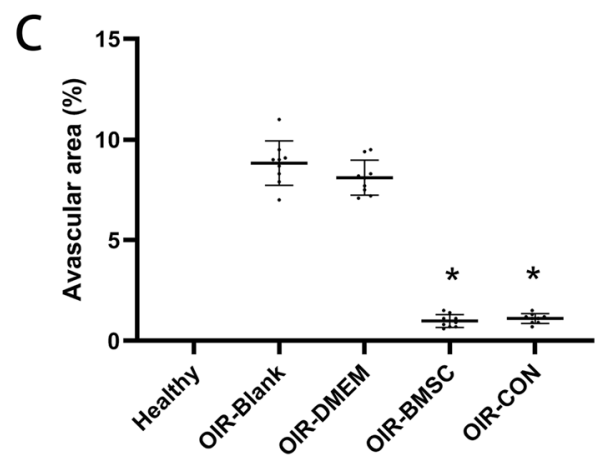

D
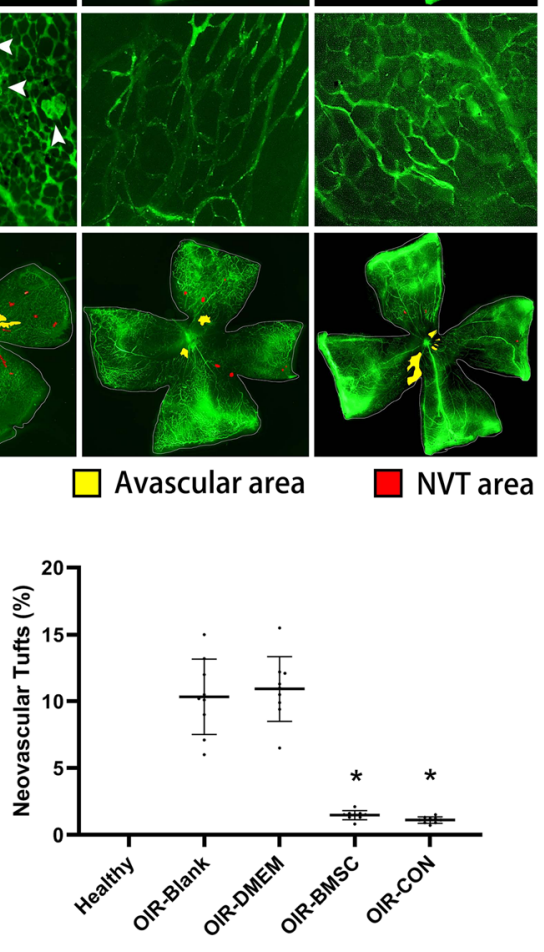

Fig. 1 Neovascularization was inhibited after BMSC or Conbercept injection. a Schematic process of establishing an OIR animal model by exposure to $75 \%$ oxygen from postnatal day 7 (P7) to P12 and return to room air with or without intravitreal injection. b P17 retinal flat-mount revealed neovascular tufts (NVT, arrowheads) and avascular areas developed after high oxygen exposure (OIR-blank and OIR-DMEN) but shrinked following BMSC (OIR-BMSC) or Conbercept (OIR-CON) injection. c Avascular areas were presented as percentages to the whole retina; both BMSC and Conbercept injection significantly reduced avascular areas. $\mathbf{d}$ Similar quantification was calculated in regard to the neovascular tufts (NVT) areas. ${ }^{*}, P<0.05$ versus OIR-blank; $n=9$ 
OIR-blank and OIR-DMEM groups (red and yellow zone, Fig. 1b). The retinas from hyperoxygen-exposed mice treated with either BMSC or Conbercept showed fine radial branching pattern in the vessels and significantly reduced the neovascular tufts and the avascular areas. The avascular areas and the neovascular tufts in OIR-BMSC and OIR-CON groups were significantly smaller than those in OIR-blank and OIRDMEM groups $(P<0.05)$, while no significant difference existed between OIR-BMSC group and OIRCON group (Fig. 1c, d).

In the whole mount retinal digests, the endothelial nuclei and pericytes nuclei were elongated and spherical, respectively. The endothelial nuclei decreased in the capillaries of OIR-blank group and OIR-DMEM group, as observed that fusiform nuclei relatively increased in OIR-blank and OIR-DMEM groups. Acellular capillaries were calculated per $\mathrm{mm}^{2}$. Compared with hyperoxygen exposure without treatment, both BMSC and Conbercept treatment significantly reduced the number of acellular capillaries in the retinas $(P<$ 0.05 , Fig. 2). Further comparison revealed no significant difference between BMSC and Conbercept treatment $(P>0.05)$.

\section{BMSC recruitment after intravitreal injection}

To examine whether BMSC was specifically recruited to the sites of retinal neovascularization, we detected the expression of red fluorescent protein (RFP) in the retinas of 3 days (P15), 5 days (P17) and 10 days (P22) after BMSC injection. The results showed few RFPpositive cells in the retinal vascular areas at P15. The cells were increased and dispersed around the retinal vascular sites at P17, indicating that the BMSC migrate closer to the vessels. Retinal flat-mount at P22 revealed that the cells participated in the formation of vascular structure (Fig. 3).

\section{Retinal histology and apoptosis assay}

The severity of proliferation in the vitreous after injection is proportional to the concentration of BMSCs (Fig. 4). Therapeutic dose was thereby tapered to $5 \times 10^{6}$ cells $/ \mathrm{ml}$. The extent of neovascularization was quantified in the retinal sections by counting the average number of vascular nuclei that extend beyond the inner limiting membrane into the vitreous body. There were no neovascular nuclei in the healthy group. Both OIR-blank group and OIR-DMEM group showed active neovascularization, and are characterized by lumen-like structure
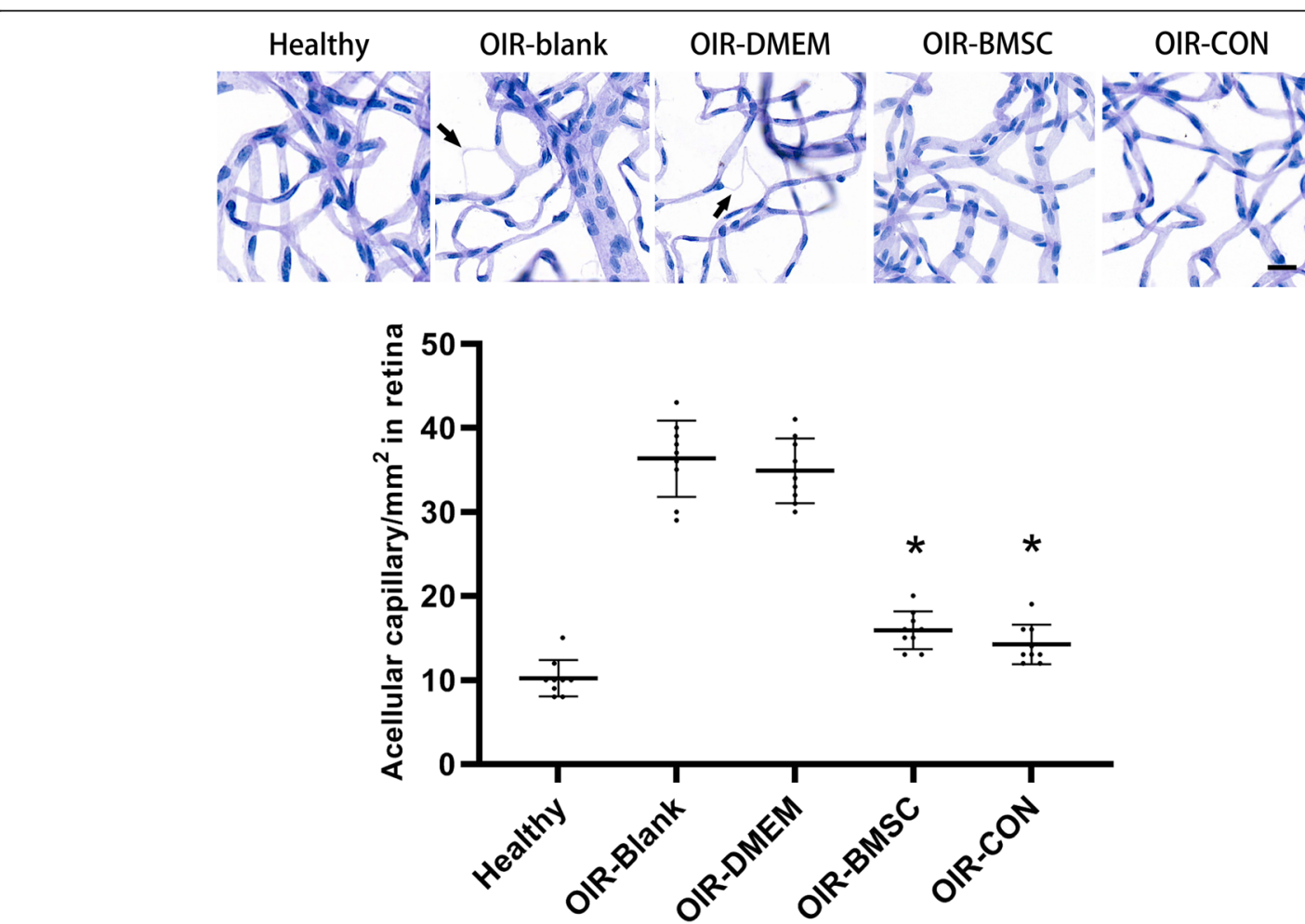

Fig. 2 Retinal vascular density and acellular capillaries among groups. Retinal flat-mount digestion showed vascular density was improved after BMSC or Conbercept injection. Acellular capillaries (arrows) appeared in OIR-blank and OIR-DMEM but reduced in OIR-BMSC and OIR-CON. Quantification revealed significant improvement in the groups receiving BMSC or Conbercept injection (P17). ${ }^{*}, P<0.05$ versus OIR-blank; $n=9$; Bar $=20 \mu \mathrm{m}$ 


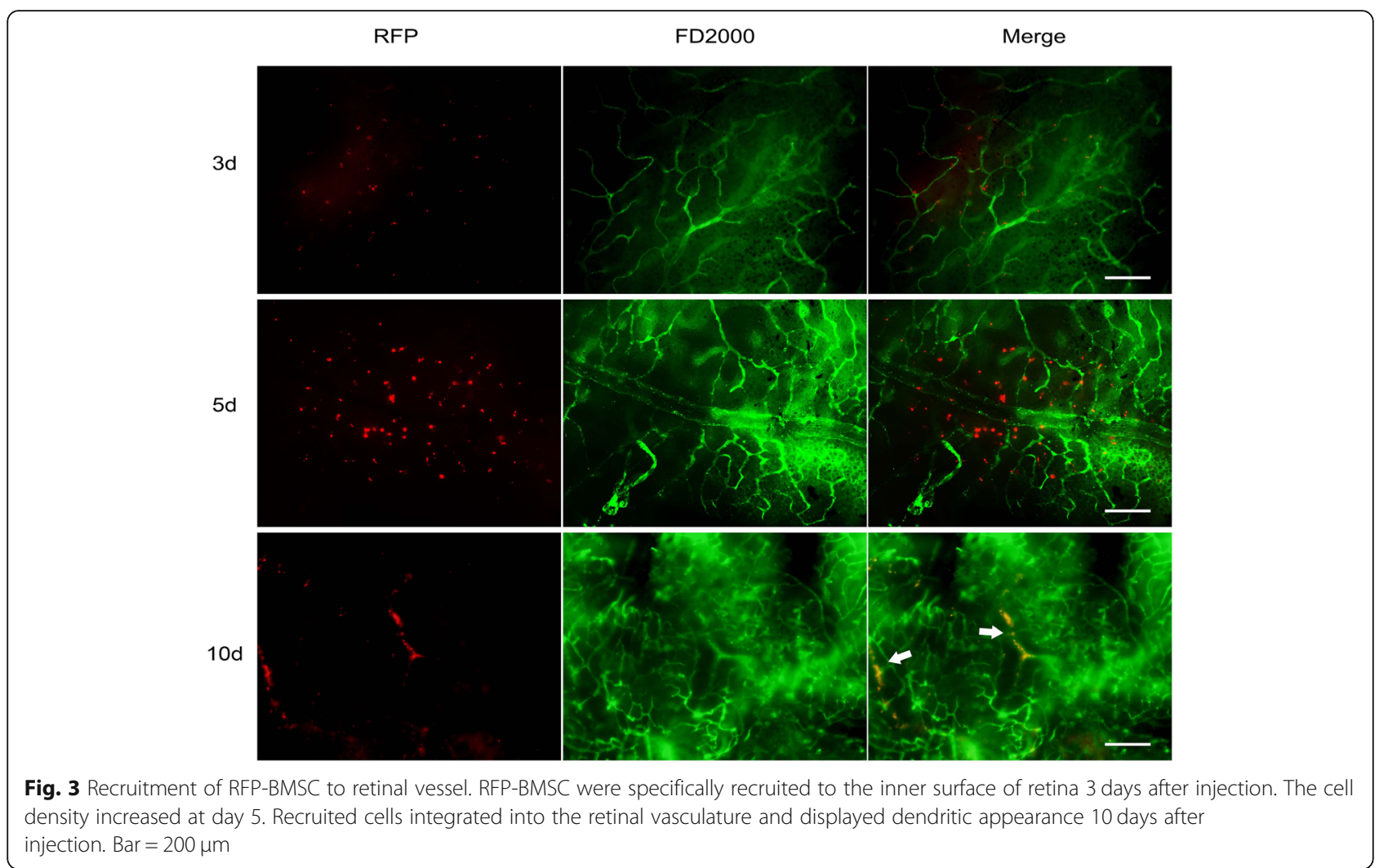

accompanied with nuclei located above the inner limiting membrane. In contrast, fewer blood vessels were observed beyond the inner limiting membrane in OIRBMSC group and OIR-CON group (Fig. 5). Neovascular nuclei in OIR-BMSC group and OIR-CON group were significantly lower than those in OIR-blank group $(P<$ 0.05). Intravitreal injection of either BMSC or Conbercept significantly attenuated the neovascularization response with no difference between BMSC and Conbercept $(P>0.05)$.
We also performed the TUNEL assay to determine the apoptotic response in the retina during vascular tuft regression. BMSC injection significantly reduced the number of TUNEL-positive cells in contrast to OIR-blank group $(P<0.05)$, while Conbercept injection showed no significant difference (Fig. 6). Further comparison in regard to the apoptosis of retinal cell between BMSC and Conbercept treatment also revealed significant difference $(P<0.05)$. This suggested that the BMSC have antiapoptotic effects in hypoxic environment.
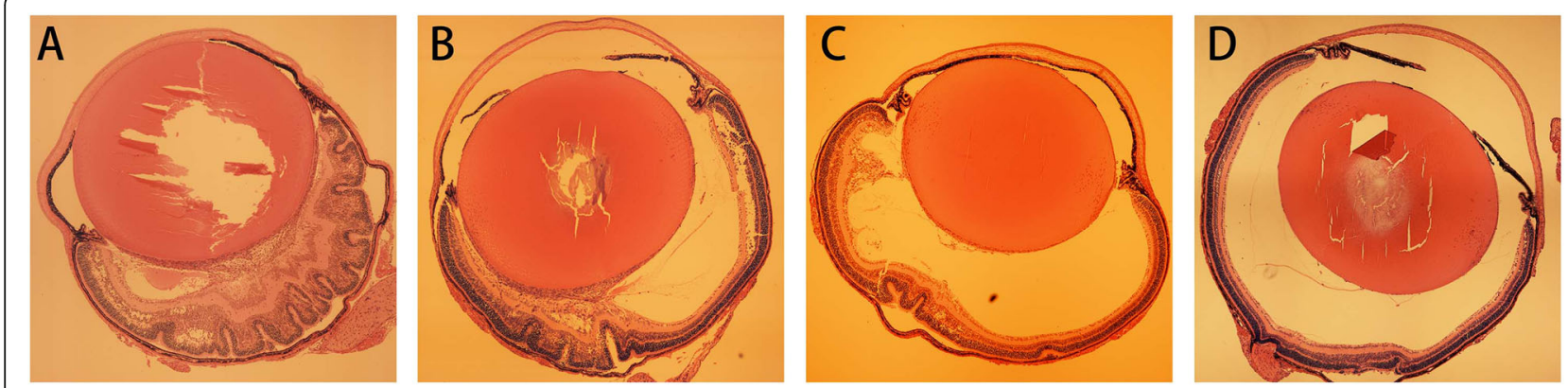

Fig. 4 Vitreoretinal appearance after BMSC injection by a series of concentrations. a Cell concentration at $1 \times 10^{8}$ cells $/ \mathrm{ml}$ resulted in severe retinal traction and proliferation in the vitreous. $\mathbf{b}$ Traction and proliferation reduced when the cell concentration was adjusted to $5 \times 10^{7}$ cells/ $\mathrm{ml}$. c Vitreoretinal appearance was improved at $1 \times 10^{7} \mathrm{cell} / \mathrm{s} / \mathrm{ml}$, but mild traction and proliferation still existed. $\mathbf{d}$ Traction and proliferation disappeared when tapering to $5 \times 10^{6}$ cells $/ \mathrm{ml}$ 


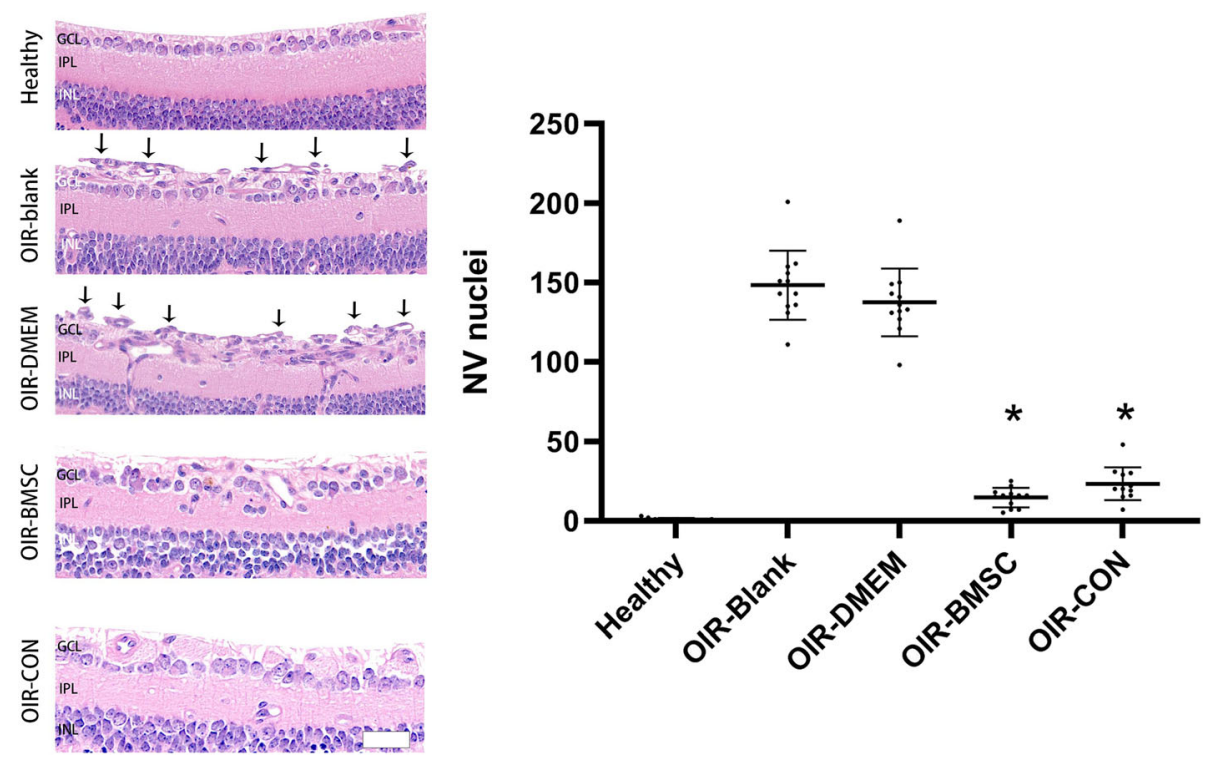

Fig. 5 Histological analysis of neovascularization (NV) among groups. Abnormal NV extended beyond the inner limiting membrane in OIR-blank group and OIR-DMEM group, forming lumen-like structures (arrows), while the inner surface of healthy retina appeared clear (P17). Neovascular nuclei in OIR-BMSC group and OIR-CON group significantly reduced in contrast to OIR-blank by random field counting in posterior retina, while no significance existed between OIR-BMSC group and OIR-CON group. ${ }^{*}, P<0.05$ versus OIR-blank; $n=12 ;$ Bar $=50 \mu \mathrm{m}$

\section{Discussion}

Several previous studies have provided evidence regarding the role of BMSC in ocular neovascularization. In this study, we found that the BMSC remodeled the vascular network and reduced the avascular areas and neovascularization. Similar effects were observed in multiple animal models of retinal neovascularization by using human BMSC [11]. However, we specifically examined the role of BMSC and compared with
Conbercept, which is an important anti-VEGF drug that is clinically used for the treatment of ocular neovascularization. Although higher doses of intravitreal injection of BMSC tend to induce proliferative retinopathy, our results revealed that lower dose injection of BMSC yielded protective effects against retinal neovascularization, but not inferior to anti-VEGF therapy.

The putative retinal neovascularization tropism is primarily based on the innate physiological ability of BMSC
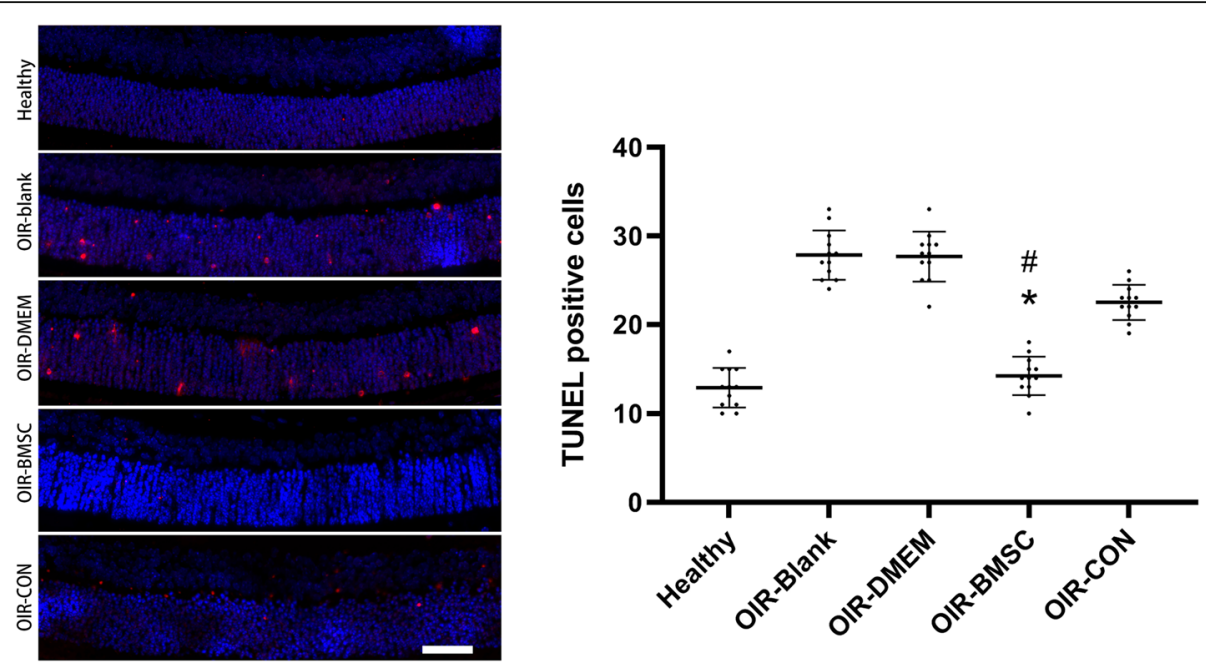

Fig. 6 BMSC injection inhibited apoptosis in the retinal cells. Apoptosis mainly occurred in the retinas of OIR-blank group, OIR-DMEM group and OIR-CON group, while fewer apoptotic cells appeared in OIR-BMSC group or healthy group. Quantification of TUNEL-positive cells among groups by random field counting in posterior retina revealed significant inhibition of apoptosis in the group receiving BMSC in contrast to OIR-Blank and OIR-CON (P17). * $P<0.05$ versus OIR-Blank; $\#, P<0.05$ versus OIR-CON; $n=12 ; B a r=50 \mu \mathrm{m}$ 
to move to the sites of inflammation and repair the tissues [12]. Retinal neovascularization is a component of several key processes associated with ischemic retinopathies [13]. Hyperoxygen-exposure followed by room air at P12 resulted in retinal hypoxia, leading to elevated levels of hypoxia-related cytokines that contribute to the formation of avascular areas and retinal neovascularization. These cytokines also contribute to the differentiation of BMSC into endothelial-like cells [14], which is partly the reason as to why BMSC injection exerted therapeutic effects. Apart from angiographic improvement by BMSC, significantly reduced retinal cell death was also observed in the OIR mice. Although no trophic factors were detected in this study, our previous report suggested that the trophic or paracrine effect of BMSC may promote this tissue repair [15].

Specific recruitment to the location of ischemic area is required for BMSC to participate in tissue repair. The interaction between stromal cell-derived factor-1 (SDF1) and CXC-motif-chemokine receptor 4 (CXCR4) is generally considered to be essential for the recruitment of BMSC during injury. Our previous study reported that the stromal cell-derived factor 1a (SDF-1a) stimulated MSC elicited superior effects in terms of both MSC migration and inhibition of apoptosis [16]. But recently, the hypothesis that VEGF and SDF-1 promotes the recruitment of bone marrow-derived cells in retinal neovascularization is gaining acceptance [17]. Therefore, further investigation into BMSC recruitment during retinal neovascularization is necessary to understand how these cells participate in vascular remodeling.

Retinal neovascularization is tightly regulated by a dynamic and natural equilibrium between local proangiogenic and antiangiogenic factors [1, 18, 19]. Among these factors, VEGF and PEDF are the major components, and retinal neovascularization involves disequilibrium of VEGF/PEDF. Rebalance of these angiogenic stimulators and inhibitors might play a crucial role in attenuating retinal damage [20]. Whether BMSC play a role in equilibrium between VEGF and PEDF requires further investigations. Interestingly, there was significant difference in the TUNEL assay where the BMSC injection showed better performance. Also, further investigations into the functional recovery are required to determine whether BMSC injection yields better visual outcomes.

Pathological angiogenesis is a hallmark in the pathogenesis of retinopathy of prematurity, and is most evident during the hypoxic phase following hyperoxic exposure [21]. The animal model of OIR in this study simulated the hyperoxic and hypoxic phase in the retinopathy of prematurity though oxygen control. Although our findings provide a therapeutic strategy against retinopathy of prematurity, attention should be paid on the induction of potential proliferative vitroretinopathy with BMSC injection. Still we were able to provide the therapeutic effect by tapering the injection dose. Safety is the most important concern in the application of BMSC against retinal neovascularization. Several clinical trials regarding the safety of these cells in retinal disorders have been put forwarded and showed satisfactory results [22-24]. Therefore, the application of BMSC in retinal neovascularization is highly anticipated despite these limitations.

\section{Conclusions}

Our study suggested that BMSC inhibit neovascularization and exert a protective effect on OIR. This protective effect is associated with the recruitment of BMSC to the site of lesion and reduction in the retinal cell apoptosis. Our study provides an alternative therapeutic strategy to inhibit neovascularization in neovascular disease by BMSC injection instead of current anti-VEGF therapy.

\section{Abbreviations}

BMSC: Bone marrow-derived mesenchymal stem cells; OIR: Oxygen-induced retinopathy; VEGF: Vascular endothelial growth factor

\section{Acknowledgements}

None.

\section{Author' contributions}

WX and WJC designed the study, collected data, and wrote the paper. XC participated in the collection and interpretation of some data. GX conceived the idea and interpreted results. All authors have read and approved the submission of this manuscript.

\section{Funding}

This work was supported by grants from the National Natural Science Foundation of China (No. 81770948), Natural Science Foundation of Fujian Province (No. 2017 J05125) and Health Comission of Fujian Province (No. 2017-ZQN-42). However, the funders had no role in study design, data collection and analysis, decision to publish, or preparation of the manuscript.

Availability of data and materials

The datasets used and analysed during the current study are available from the corresponding author on reasonable request.

\section{Ethics approval and consent to participate}

All animal experiments were approved by the animal ethical committee of the Fujian Medical University, and performed in accordance with the National Institutes of Health Guide for the Use of Laboratory Animals [25].

Consent for publication

Not applicable.

\section{Competing interests}

The authors declare that they have no competing interests.

Received: 13 March 2019 Accepted: 27 December 2019

Published online: 06 January 2020

\section{References}

1. Al-Shabrawey M, Elsherbiny M, Nussbaum J, Othman A, Megyerdi S, Tawfik A. Targeting neovascularization in ischemic retinopathy: recent advances. Expert Rev Ophthalmol. 2013;8(3):267-86.

2. Rosenfeld PJ, Brown DM, Heier JS, Boyer DS, Kaiser PK, Chung CY, Kim RY. Ranibizumab for neovascular age-related macular degeneration. N Engl J Med. 2006;355(14):1419-31. 
3. Yonekawa Y, Wu WC, Nitulescu CE, Chan RVP, Thanos A, Thomas BJ, Todorich B, Drenser KA, Trese MT, Capone A Jr. Progressive retinal detachment in infants with retinopathy of prematurity treated with intravitreal bevacizumab or ranibizumab. Retina. 2018;38(6):1079-83.

4. Li M, Kroetz DL. Bevacizumab-induced hypertension: clinical presentation and molecular understanding. Pharmacol Ther. 2018;182:152-60.

5. Nishijima K, Ng YS, Zhong L, Bradley J, Schubert W, Jo N, Akita J, Samuelsson SJ, Robinson GS, Adamis AP, et al. Vascular endothelial growth factor-a is a survival factor for retinal neurons and a critical neuroprotectant during the adaptive response to ischemic injury. Am J Pathol. 2007;171(1):53-67.

6. Martin DF, Maguire MG, Fine SL, Ying GS, Jaffe GJ, Grunwald JE, Toth C, Redford M, Ferris FL 3rd. Ranibizumab and bevacizumab for treatment of neovascular age-related macular degeneration: two-year results. Ophthalmol. 2012;119(7):1388-98

7. Trinh TLP, Li Calzi S, Shaw LC, Yoder MC, Grant MB. Promoting vascular repair in the retina: can stem/progenitor cells help? Eye Brain. 2016;8:113-22.

8. Wu Y, Zhao RC. The role of chemokines in mesenchymal stem cell homing to myocardium. Stem Cell Rev. 2012;8(1):243-50.

9. Hou HY, Liang HL, Wang YS, Zhang ZX, Wang BR, Shi YY, Dong X, Cai Y. A therapeutic strategy for choroidal neovascularization based on recruitment of mesenchymal stem cells to the sites of lesions. Mol Ther. 2010;18(10):1837-45

10. Tang YL, Zhao Q, Qin X, Shen L, Cheng L, Ge J, Phillips MI. Paracrine action enhances the effects of autologous mesenchymal stem cell transplantation on vascular regeneration in rat model of myocardial infarction. Ann Thorac Surg. 2005;80(1):229-36.

11. Wang JD, An Y, Zhang JS, Wan XH, Jonas JB, Xu L, Zhang W. Human bone marrow mesenchymal stem cells for retinal vascular injury. Acta Ophthalmol. 2017;95(6):e453-61.

12. Ozawa K, Sato K, Oh I, Ozaki K, Uchibori R, Obara Y, Kikuchi Y, Ito T, Okada T, Urabe $M$, et al. Cell and gene therapy using mesenchymal stem cells (MSCs). J Autoimmun. 2008;30(3):121-7.

13. Campochiaro PA. Ocular neovascularization. J Mol Med (Berl). 2013;91(3):311-21.

14. Wang $N$, Zhang $R$, Wang SJ, Zhang CL, Mao LB, Zhuang CY, Tang YY, Luo $X G$, Zhou $H$, Zhang TC. Vascular endothelial growth factor stimulates endothelial differentiation from mesenchymal stem cells via rho/myocardinrelated transcription factor--a signaling pathway. Int J Biochem Cell Biol. 2013:45(7):1447-56.

15. Xu W, Wang X, Xu G, Guo J. Basic fibroblast growth factor expression is implicated in mesenchymal stem cells response to light-induced retinal injury. Cell Mol Neurobiol. 2013;33(8):1171-9.

16. Xu W, Wang XT, Xu GX, Guo J, Huang LB. Stromal cell-derived factor 1alphastimulated mesenchymal stem cells confer enhanced protection against light-induced retinal degeneration in rats. Curr Eye Res. 2014;39(1):69-78

17. Campochiaro PA. Molecular pathogenesis of retinal and choroidal vascular diseases. Prog Retin Eye Res. 2015;49:67-81.

18. Gao G, Li Y, Zhang D, Gee S, Crosson C, Ma J. Unbalanced expression of VEGF and PEDF in ischemia-induced retinal neovascularization. FEBS Lett. 2001;489(2-3):270-6

19. Jaffe GJ, Ciulla TA, Ciardella AP, Devin F, Dugel PU, Eandi CM, Masonson H, Mones J, Pearlman JA, Quaranta-El Maftouhi M, et al. Dual antagonism of PDGF and VEGF in neovascular age-related macular degeneration: a phase $\mathrm{Ilb}$, multicenter, randomized controlled trial. Ophthalmol. 2017;124(2):224-34.

20. Zheng Z, Chen H, Ke G, Fan Y, Zou H, Sun X, Gu Q, Xu X, Ho PC. Protective effect of perindopril on diabetic retinopathy is associated with decreased vascular endothelial growth factor-to-pigment epithelium-derived factor ratio: involvement of a mitochondria-reactive oxygen species pathway. Diabetes. 2009;58(4):954-64.

21. Zhou R, Zhang S, Gu X, Ge Y, Zhong D, Zhou Y, Tang L, Liu XL, Chen JF. Adenosine A2A receptor antagonists act at the hyperoxic phase to confer protection against retinopathy. Mol Med. 2018;24(1):41.

22. Siqueira RC, Messias A, Messias K, Arcieri RS, Ruiz MA, Souza NF, Martins LC, Jorge R. Quality of life in patients with retinitis pigmentosa submitted to intravitreal use of bone marrow-derived stem cells (Reticell -clinical trial). Stem Cell Res Ther. 2015;6:29.

23. Siqueira RC, Messias A, Voltarelli JC, Scott IU, Jorge R. Intravitreal injection of autologous bone marrow-derived mononuclear cells for hereditary retinal dystrophy: a phase I trial. Retina. 2011;31(6):1207-14.
24. Park SS, Bauer G, Abedi M, Pontow S, Panorgias A, Jonnal R, Zawadzki RJ, Werner JS, Nolta J. Intravitreal autologous bone marrow CD34+ cell therapy for ischemic and degenerative retinal disorders: preliminary phase 1 clinical trial findings. Invest Ophthalmol Vis Sci. 2014;56(1):81-9.

25. NIH (National Institutes of Health U.S.A). Guide for the care and use of laboratory animals. Washington, D.C.: The National Academies Press; 2011.

\section{Publisher's Note}

Springer Nature remains neutral with regard to jurisdictional claims in published maps and institutional affiliations.
Ready to submit your research? Choose BMC and benefit from:

- fast, convenient online submission

- thorough peer review by experienced researchers in your field

- rapid publication on acceptance

- support for research data, including large and complex data types

- gold Open Access which fosters wider collaboration and increased citations

- maximum visibility for your research: over $100 \mathrm{M}$ website views per year

At BMC, research is always in progress.

Learn more biomedcentral.com/submissions 